\title{
DISCAPACIDAD EN MÉXICO, POLÍTICAS PÚBLICAS Y PROTECCIÓN JURÍDICA
}

\author{
María Leoba Castañeda Rivas* \\ Recibido: Febrero 7 de 2016 \\ Aprobado: Mayo 21 de 2016
}

\begin{abstract}
RESUMEN
Las personas con discapacidad enfrentan numerosos obstáculos en su vida, suelen tener menos oportunidades en el ámbito económico, educativo, laboral, deportivo, cultural, social, entre otros; el efectivo acceso a sus derechos humanos se ve mermado por la discriminación social que sufren debido a su condición.

Por ello los estados en el orden Internacional y Nacional, reconocen los derechos humanos de todas las personas sin distinción alguna, y es así que éstos adquieren la obligación de adoptar las medidas necesarias para garantizar el acceso a los derechos humanos a este sector de la población.

De tal suerte que en las últimas décadas se ha incrementado la promoción de los derechos humanos de este grupo vulnerable, ya que es fundamental promover el reconocimiento de los derechos humanos, sumando esfuerzos entre la sociedad y el gobierno para que las personas con discapacidad no sufran discriminación por su condición.
\end{abstract}

Palabras clave: Discapacidad, políticas públicas, protección jurídica, derechos humanos, protección de derechos

\section{DISABILITY IN MEXICO, PUBLIC POLICIES AND LEGAL PROTECTION}

\footnotetext{
"Es Doctora en Derecho por la UNAM, y Catedrática de Carrera de Tiempo Completo de la Facultad de Derecho y de la División de Estudios de Posgrado. Es Doctora Honoris Causa por la Universidad Autónoma del Estado de Morelos. Es Miembro del Consejo Editorial de diversas y prestigiadas publicaciones jurídicas, tanto de México como del extranjero. Evaluadora Par de los Programas Nacionales de Posgrado de Calidad del Consejo Nacional de Ciencia y Tecnología (CONACYT). Investigadora Nacional Nivel I del Consejo Nacional de Ciencia y Tecnología (CONACYT). Primera mujer Directora de la Facultad de Derecho de la UNAM, en más de 459 años.
} 


\begin{abstract}
People with disabilities face many obstacles in their lives, often have fewer opportunities in the economic, educational, labor, sports, cultural, social area, among others; the effective access to their human rights is undermined by social discrimination due to their condition.
\end{abstract}

For this reason, States in the International and national order, recognize the human rights of all individuals without any distinction, and it is so they acquire the obligation to adopt the necessary measures to guarantee the access to the human rights to this sector of the population.

In such a way that in the last decades has increased the promotion of human rights of this vulnerable group, since it is essential to promote the recognition of human rights, adding efforts between society and the government in order that people with disabilities do not suffer discrimination because of their condition.

Keywords: Disability, public policies, legal protection, human rights, rights protection.

\title{
DEFICIÊNCIA NO MÉXICO, POLÍTICAS PÚBLICAS E PROTEÇÃO LEGAL RESUMO
}

As pessoas com deficiência enfrentam muitos obstáculos na sua vida, muitas vezes têm menos oportunidades no âmbito económico, educacional, do trabalho, esportes, cultural, social, entre outros; o acesso efetivo aos seus direitos humanos é prejudicado pela discriminação social que eles sofrem devido à sua condição.

Portanto, os estados na ordem nacional e internacional, reconhecem os direitos humanos de todas as pessoas, sem distinção, e assim estes adquirem a obrigação de tomar as medidas necessárias para garantir o acesso aos direitos humanos a este sector da população.

De tal sorte que nas últimas décadas tem se aumentado a promoção dos direitos humanos deste grupo vulnerável, uma vez que é essencial para promover o reconhecimento dos direitos humanos, acrescentando esforços entre a sociedade e o governo para que as pessoas com deficiência não sofram discriminação por causa de sua condição.

Palavras-chave: Deficiência, política pública, proteção jurídica, direitos humanos, proteção dos direitos. 


\section{1. ¿QUÉ ES LA DISCAPACIDAD?}

Según del Diccionario de la Real Academia Española por discapacidad se puede entender "condición de discapacitado. Manifestación de una discapacidad" (Real Academia Española, 2014, 23\% ed.); lo anterior quiere decir que la discapacidad es una condición, no una enfermedad.

De acuerdo con la Organización Mundial de la Salud, la discapacidad "es un término general que abarca las deficiencias, las limitaciones de la actividad y las restricciones de la participación. Las deficiencias son problemas que afectan a una estructura o función corporal; las limitaciones de la actividad son dificultades para ejecutar acciones o tareas, y las restricciones de la participación son problemas para participar en situaciones vitales.

Por consiguiente, la discapacidad es un fenómeno complejo que refleja una interacción entre las características del organismo humano y las características de la sociedad en la que vive". (Organización Mundial de la Salud, 2015)

Por ello, en la Convención sobre los Derechos de las Personas con Discapacidad (2008), se reconoce que la discapacidad "es un concepto que evoluciona y que resulta de la interacción entre las personas con deficiencias y las barreras debidas a la actitud y al entorno que evitan su participación plena y efectiva en la sociedad, en igualdad de condiciones con las demás"'. (p.3)

Lo anterior quiere decir que los derechos humanos son de todos sin excepción alguna, toda vez que son inherentes a la persona, es decir, a la dignidad de la misma, por ello los Estados partes de la Convención tienen la obligación de adoptar las medidas necesarias que permitan garantizar sus derechos a este grupo de personas para alcanzar el desarrollo de sus planes de vida.

\section{IGUALDAD O DISCRIMINACIÓN: MUJERES CON DISCAPACIDAD}

Cuando hablamos de discriminación no solo podemos hacer mención a un género o grupo de personas, es decir, referirnos a los hombres, mujeres, niños, niñas, adultos mayores, en particular, puesto que no

1 Convención sobre los Derechos de las Personas con Discapacidad, p. 3, disponible en: <https://www. scjn.gob.mx/libro/InstrumentosConvencion/PAG0313.pdf>, (visitada el 29 de diciembre del 2015). 
existe exclusividad, ya que la discapacidad no conoce de fronteras, por ello corresponde a la sociedad en colaboración con el gobierno el buscar alcanzar el mayor grado posible de satisfacción de los derechos de las personas con discapacidad.

Ahora bien, por persona discapacitada podemos entender que es aquella que "padece una disminución física, sensorial o psíquica que la incapacita total o parcialmente para el trabajo o para otras tareas ordinarias de la vida”. (RAE, 2014, $23^{\circ}$ ed.).

En el año 2010 se presentó la Encuesta Nacional de Percepción de Discapacidad en Población Mexicana, la cual arrojó como resultados que existen "6 millones 580 mil 841 mexicanos que viven con algún tipo de discapacidad, es decir, el $6.2 \%$ del total de la población. De este porcentaje el $52.2 \%$ son mujeres y el $47.5 \%$ son hombres". (Encuesta Nacional de Percepción de Discapacidad, 2010).

Es de destacar que las mujeres con discapacidad ocupan el mayor porcentaje de este sector y forman parte de un grupo vulnerable, de tal suerte que sufren una doble discriminación, es decir, por su discapacidad y por su género, debido a que enfrentan diversos obstáculos en su vida como son la alimentación, salud, educación, vivienda, oportunidades laborales, ingresos, entre otros.

Por tal motivo, el Estado se debe dar a la tarea de implementar políticas públicas para combatir la discriminación en contra de este sector de la población, proteger y garantizar sus derechos humanos, sin que esto implique dar un trato desfavorable o diferenciado a los hombres, ya que la protección de los derechos de todas las personas debe ser acorde con los principios de igualdad y no discriminación.

Relacionado con lo anterior, la Suprema Corte de Justicia de la Nación ha emitido el siguiente criterio en el que se señala:

DERECHO HUMANO A LA IGUALDAD JURÍDICA. CONTENIDO Y ALCANCES DE SU DIMENSIÓN SUSTANTIVA O DE HECHO.

Esta modalidad del principio constitucional de igualdad jurídica impone a las distintas autoridades del Estado la obligación de llevar a cabo ciertos actos que tiendan a obtener una correspondencia de oportunidades entre distintos grupos sociales y sus integrantes y el resto de la 
población; por ende, se cumple a través de una serie de medidas de carácter administrativo, legislativo o de cualquier otra índole que tengan como finalidad evitar que se siga produciendo una diferenciación injustificada o discriminación sistemática o que se reviertan los efectos de la marginación histórica y/o estructural de un grupo social relevante. A estas medidas se les pueden catalogar como acciones positivas o de igualación positiva. Ejemplos de las primeras pueden ser ciertas políticas públicas que tengan como sujetos a las mujeres o a las personas con algún grado de discapacidad y que busquen otorgarles bienes o servicios adicionales para que alcancen un mismo grado de oportunidades para el ejercicio de sus derechos; mientras que ejemplos de las segundas consisten en las cuotas o los actos específicos de discriminación inversa en favor de una persona que pertenezca a un determinado grupo social. En algunos de esos casos, se dará formalmente un trato desigual de iure o de facto respecto de otras personas o grupos, pero el mismo deberá estar justificado precisamente por la consecución de la igualdad de hecho y tendrá que cumplir con criterios de proporcionalidad. Con base en lo anterior, se estima que no existe una lista exhaustiva o definitiva sobre las medidas que puedan llevarse a cabo para la obtención de la igualdad de hecho; dependerá tanto de las circunstancias fácticas, sociales, económicas, culturales, políticas o jurídicas que imperen al momento de tomarse la decisión, como de la entidad o autoridad que vaya a llevar a cabo la medida correspondiente con un amplio margen de apreciación. Sin embargo, lo que es común a todos estos tipos de medidas es que buscan conferir un mismo nivel de oportunidades para el goce y ejercicio de los derechos humanos de los miembros de ciertos grupos sociales, los cuales se caracterizan por ser $\mathrm{o}$ haber sido objeto de una discriminación o exclusión recurrente y sistemática. Estos grupos se definen por su existencia objetiva e identidad colectiva, así como por su situación de subordinación y poder político disminuido frente a otros grupos; no obstante, aunque no existe una delimitación exhaustiva de tales grupos sociales relevantes para la aplicación de esta faceta del principio de igualdad, el artículo $1^{\circ}$, último párrafo, de la Constitución Federal, ha establecido distintas 
categorías sospechosas que sirven como punto de partida para su identificación. (Gaceta del Semanario Judicial de la Federación, 2014, libro III, Tomo I, p. 644.)

Del anterior criterio se desprenden puntos importantes en relación con los principios de igualdad y no discriminación, al señalarse que, resulta válido dar un trato desigual de iure o de facto respecto de personas o grupo de personas, como es el caso de las mujeres, ya que dependen de circunstancias sociales, económicas, culturales, políticas o jurídicas que se encuentren presentes al momento de tomar la decisión de dar un trato desigual por estar expuestas a un mayor riesgo, para asegurar la protección de los derechos humanos de esas personas o grupos, garantizando con ello un mismo nivel de oportunidades para el goce y ejercicio de los derechos humanos por ser objeto de discriminación.

Por lo anterior, en México contamos con la Ley General para la Inclusión de las Personas con Discapacidad y la Ley Federal para Prevenir y Eliminar la Discriminación, las cuales fueron realizadas a la luz de los principios de igualdad y no discriminación como lo señala el siguiente criterio:

DISCAPACIDAD. EL ANÁLISIS DE LAS DISPOSICIONES EN LAMATERIADEBE REALIZARSE A LA LUZ DE LOS PRINCIPIOS DE IGUALDAD Y DE NO DISCRIMINACIÓN.

La regulación jurídica tanto nacional como internacional que sobre personas con discapacidad se ha desarrollado, tiene como finalidad última evitar la discriminación hacia este sector social y, en consecuencia, propiciar la igualdad entre individuos. Así, las normas en materia de discapacidad no pueden deslindarse de dichos propósitos jurídicos, por lo que el análisis de tales disposiciones debe realizarse a la luz de los principios constitucionales de igualdad y no discriminación. (Semanario Judicial de la Federación y su Gaceta, 2013, libro XVI, tomo I, p. 630)

Como ya lo hemos señalado, los principios de igualdad y no discriminación son principios rectores que rigen los derechos humanos de toda persona los cuales provienen de la dignidad del ser humano por el Estado tiene la obligación de promover, respetar, proteger y garantizar los derechos humanos de todos sin distinción alguna. 


\section{MARCO JURÍDICO INTERNACIONAL Y NACIONAL EN MATERIA DE DISCAPACIDAD}

Existen instrumentos internacionales que contienen diversas disposiciones que protegen los derechos humanos de las personas con discapacidad; de ellos se advierte la preocupación de los gobiernos de nivel internacional por erradicar cualquier tipo de discriminación que pudiera sufrir este grupo de personas.

\section{a) Ámbito Internacional}

\section{Declaración Universal de Derechos Humanos}

La Declaración Universal de Derechos Humanos fue proclamada por la Asamblea General de las Naciones Unidas en 1948, poco después de haber finalizado la Segunda Guerra Mundial; el propósito de esta Asamblea con dicha Declaración era traer paz a todo el mundo luego de las atrocidades vividas en ese tiempo.

Dicha Declaración refleja dolorosas experiencias vividas y se insiste en la dignidad, la igualdad y la libertad de las personas, en la necesidad de la paz y la cooperación entre los Estados.

En el preámbulo de este importante instrumento internacional se señala que "la libertad, la justicia y la paz en el mundo tienen por base el reconocimiento de la dignidad intrínseca y de los derechos iguales e inalienables de todos los miembros de la familia humana." (Declaración Universal de los Derechos Humanos, 1948). De esta reflexión se infiere que los derechos humanos tienen como base la dignidad de la persona, los cuales se encuentran protegidos por un régimen de Derecho.

Por ello, en el artículo $1^{\circ}$ de este instrumento internacional, se señala que todos los seres humanos nacen libres e iguales en dignidad y derechos; posteriormente en su artículo $7^{\circ}$ se reconoce que todos tienen derecho a igual protección de la ley contra toda discriminación, es decir, ni por motivos de discapacidad se pueden limitar los derechos de una persona, toda vez que se protegen los derechos humanos de todos sin distinción alguna.

\section{Pacto Internacional de Derechos Civiles y Políticos}

Fue adoptado en Nueva York el 16 de diciembre de 1966, cuya adhesión de México se llevó a cabo el 24 de marzo de 1981, en el Pacto Internacional de Derechos Civiles y Políticos, se consagran los deberes 
que los individuos tienen respecto de otros individuos y la obligación de los Estados partes a garantizar a hombre y mujeres la igualdad en el goce de todos sus derechos civiles y políticos así:

Todas las personas son iguales ante la ley y tienen derecho sin discriminación a igual protección de la ley. A este respecto, la ley prohibirá toda discriminación y garantizará a todas las personas protección igual y efectiva contra cualquier discriminación por motivos de raza, color, sexo, idioma, religión, opiniones políticas o de cualquier índole, origen nacional o social, posición económica, nacimiento o cualquier otra condición social. (Pacto Internacional de Derechos Civiles y Políticos, 1966, art 26)

De lo anterior se deduce que toda discriminación por motivo de discapacidad, queda prohibida toda vez que se deben garantizar los derechos a todos preservando la dignidad de la persona.

\section{Pacto Internacional de Derechos Económicos, Sociales y Culturales}

Este instrumento internacional fue adoptado en Nueva York el 16 de diciembre de 1966 y publicado en México en el Diario Oficial de la Federación el 12 de mayo de 1981; los Estados partes de dicho pacto se comprometen a garantizar el ejercicio de los derechos que en él se enuncian sin discriminación alguna por motivos de raza, color, sexo, idioma, religión opinión política o de otra índole, origen nacional o social, posición económica, nacimiento, o cualquier otra condición social.

De igual forma, en este instrumento internacional se garantiza la protección de los derechos humanos de toda persona, sin importar su condición como es el caso de las personas con discapacidad, asegurándose por igual a los hombres y mujeres todos los derechos económicos, sociales y culturales enunciados en el pacto.

\section{La Convención sobre los Derechos de las Personas con Discapacidad}

Dicha Convención fue ratificada por México el 17 de diciembre de 2007 y entró en vigencia el 3 de mayo de 2008; en ella se encuentran articulados los derechos humanos de las personas con discapacidad, es así que los Estados partes se

(...) comprometen a reconocer estándares mínimos de protección de los derechos contenidos en dicho instrumento. 
Esto tiene una doble lectura, por un lado que la Convención no tiene como objetivo remplazar la ley de los Estados sino simplemente fijar topes mínimos que el Estado debe respetar, y por otro lado, y como consecuencia de lo anterior que, de existir conflicto o colisión entre la que dice ese tratado y las leyes internas, estas últimas (sic) deben reformarse. (Artigue \& Palacios, 2008, p. 26)

En relación con lo anterior, el Estado Mexicano ha establecido en la Constitución Política de los Estados Unidos Mexicanos, lo siguiente:

Queda prohibida toda discriminación motivada por origen étnico o nacional, el género, la edad, las discapacidades, la condición social, las condiciones de salud, la religión, las opiniones, las preferencias sexuales, el estado civil o cualquier otra que atente contra la dignidad humana y tenga por objeto anular o menoscabar los derechos y libertades de las personas. (art. 1)

Es así que toda discriminación en contra de cualquier persona por razón de discapacidad constituye una vulneración a la dignidad humana, entendida esta "como un atributo inherente a la persona humana que la hace merecedora de respeto y que delimita un ámbito de prerrogativas que se le deben garantizar, a fin de que tenga una existencia plena y compatible con su propia naturaleza". (Suprema Corte de Justicia de la Nación, 2013, p. 5)

En esa tesitura, no se debe perder de vista que aún existe discriminación hacia a las personas con discapacidad, por ello los Estados partes de la Convención se encuentran obligados a garantizar y promover los derechos humanos que asisten a este grupo de personas como son sus derechos civiles, culturales, económicos, políticos y sociales. De tal suerte que se establece el propósito de la Convención el cual es

Promover, proteger y asegurar el goce pleno y en condiciones de igualdad de todos los derechos humanos y libertades fundamentales por todas las personas con discapacidad, y promover el respeto de su dignidad inherente.

Las personas con discapacidad incluyen a aquellas que tengan deficiencias físicas, mentales, intelectuales $\mathrm{o}$ sensoriales a largo plazo que, al interactuar con diversas 
barreras, puedan impedir su participación plena y efectiva en la sociedad, en igualdad de condiciones con las demás. (Convención sobre los derechos de las Personas con Discapacidad, 2008, art 1)

Al respecto, en México en el Código Civil para el Distrito y Territorios Federales en materia común y para toda la República en materia Federal de 1928, señalaba:

Tienen incapacidad natural y legal:

I. Los menores de edad;

II. Los mayores de edad privados de inteligencia por locura, idiotismo o imbecilidad, aun cuando tengan intervalos lúcidos;

III. Los sordomudos que no saben leer ni escribir;

IV. Los ebrios consuetudinarios, y los que habitualmente hacen uso inmoderado de drogas enervantes. (art. 450).

Es así que, las personas arriba enumeradas carecían de capacidad y se impedía su participación plena; posteriormente, el 25 de mayo del 2000, se modificó el Código Civil para el Distrito Federal en el que se cambió la redacción para determinar lo siguiente

Tienen incapacidad natural y legal:

I. Los menores de edad;

II. Los mayores de edad que por causa de enfermedad reversible o irreversible, o que por su estado particular de discapacidad, ya sea de carácter físico, sensorial, intelectual, emocional, mental o varias de ellas a la vez, no puedan gobernarse, obligarse o manifestar su voluntad, por sí mismos o por algún medio que la supla. (art. 450)

Se puede entender que la discapacidad se divide en física, sensorial, intelectual, emocional o mental; sin embargo, en el Código no se definen, por ello se debe asegurar el goce de los derechos de las personas con discapacidad, respetando la dignidad de cualquier persona, no discriminándola por su condición; ante ello se debe asegurar su inclusión en la sociedad, otorgándole las mismas oportunidades, reconociendo la igualdad entre el hombre y la mujer en todo momento. 
Sin embargo, pese a que se habla de una igualdad entre el hombre y la mujer como un principio de la Convención, en el preámbulo de ésta, se hace un señalamiento en relación a las mujeres y las niñas con discapacidad, ya que suelen estar expuestas a un riesgo mayor dentro y fuera del hogar, por consiguiente establece que

1. Los Estados Partes reconocen que las mujeres y niñas con discapacidad están sujetas a múltiples formas de discriminación $\mathrm{y}$, a ese respecto, adoptarán medidas para asegurar que puedan disfrutar plenamente y en igualdad de condiciones de todos los derechos humanos y libertades fundamentales.

2. Los Estados Partes tomarán todas las medidas pertinentes para asegurar el pleno desarrollo, adelanto y potenciación de la mujer, con el propósito de garantizarle el ejercicio y goce de los derechos humanos y las libertades fundamentales establecidos en la presente Convención. (art. 6)

No obstante lo anterior, no se deben perder de vista los principios que rigen dicha Convención, entre los que destacan la igualdad entre el hombre y la mujer y la no discriminación, toda vez que no pueden deslindarse de dichos principios, como se aprecia en los instrumentos internacionales y en las leyes sobre la materia.

Convención Interamericana para la Eliminación de todas las formas de Discriminación contra las Personas con Discapacidad

Fue firmada el 7 de junio de 1999, entró en vigencia en el orden internacional el 14 de septiembre de 2001, en ella se reconoce que las personas con discapacidad cuentan con los mismos derechos fundamentales que cualquier otra persona pueda tener, los cuales dimana de la dignidad y la igualdad inherentes a todo ser humano, por ello es que no deben ser sometidos a discriminación por su condición.

Los objetivos principales de la Convención "son la prevención y la eliminación de todas las formas de discriminación contra las personas con discapacidad y propiciar su plena integración en la sociedad"; (Convención Interamericana para la eliminación de todas las formas de Discriminación, p. 5) en dicha Convención no se hace distinción alguna entre hombre y mujer, se protege a todos por igual.

Para lograr los objetivos, los Estados partes deben adoptar medidas legislativas de carácter social, educativo, laboral o de cualquier índole 
para eliminar la discriminación contra este sector de la población, para poder integrarlos en la sociedad; otra tarea de los Estados partes es la elaboración de programas y actividades como el empleo, el transporte, la vivienda, las comunicaciones, la educación, el deporte, el acceso a la justicia, las medidas de acceso a edificios, la prevención de cualquier forma de discriminación, programas para sensibilizar a la población, entre otros.

\section{Normas uniformes sobre la igualdad de oportunidades para las personas con discapacidad de las Naciones Unidas}

Se adoptaron con la finalidad de conseguir la igualdad de derechos de las personas con discapacidad; no son un instrumento vinculante, sin embargo, representan el compromiso de los gobiernos para alcanzar tal fin.

Las normas uniformes sobre la igualdad de oportunidades para las personas con discapacidad de las Naciones Unidas, son 22 divididas en cuatro Capítulos, en los que se establecen:

I. Requisitos para la igualdad de participación

II. Esferas previstas para la igualdad de participación

III. Medidas de ejecución

IV. Mecanismos de supervisión

De acuerdo con estas normas, los Estados deben adoptar medidas para hacer que la sociedad tome conciencia de las personas con discapacidad y sus derechos, elaborando campañas informativas a través de los medios de comunicación, velar por los programas de educación, incluir a las personas con discapacidad en actividades laborales, asegurar la prestación de atención médica y rehabilitación, y prestar servicios de apoyo para aumentar su nivel de autonomía en la vida cotidiana, entre otras medidas que les permitan ejercer sus derechos.

En ellas se incluyen las medidas que deben adoptar los Estados para eliminar los obstáculos en su entorno físico, en el acceso a la información, a la comunicación, a la educación, a la seguridad social, a la cultura, a actividades recreativas y deportivas, el empleo, todo ello basado en la igualdad de oportunidades para las personas con discapacidad.

Lo anterior quiere decir que los Estados tienen la obligación de adoptar las medidas necesarias para garantizar la igualdad de oportunidades a las 
personas con discapacidad; para ello deben crear ordenamientos jurídicos acordes con los principios de igualdad y no discriminación.

\section{b) Ámbito Nacional México}

Debido al compromiso internacional que tiene México en el tema de la protección de las personas con discapacidad, se han adoptado diversas medidas jurídicas para proteger y garantizar los derechos de estas personas; a continuación señalaremos algunos ordenamientos jurídicos de protección.

\section{Constitución Política de los Estados Unidos Mexicanos}

Nuestra Carta Magna reconoce el principio de igualdad en su artículo $4^{\circ}$, en el que se indica "El varón y la mujer son iguales ante la ley. Esta protegerá la organización y el desarrollo de la familia..." (Diario Oficial, 1974,p.1)

Así los hombres y las mujeres tienen igualdad de derechos, deberes y oportunidades en los diferentes aspectos de la vida nacional; por ello con el reconocimiento del derecho humano a la igualdad se

c...) busca garantizar la igualdad de oportunidades para que la mujer intervenga activamente en la vida social, económica, política y jurídica del país, sin distinción alguna por causa de su sexo, dada su calidad de persona; y también comprende la igualdad con el varón en el ejercicio de sus derechos y en el cumplimiento de responsabilidades. (Semanario Judicial de la Federación y su Gaceta, 2012, Libro XI, Tomo I, p. 482)

Lo anterior se puede reforzar con el contenido del último párrafo del artículo $1^{\circ}$ constitucional, que mencionamos antes, en el que se prohíbe todo tipo de discriminación que atente contra la dignidad humana y tenga por objeto menoscabar los derechos y libertades de las personas; dicho numeral adquirió mayor relevancia al publicarse la reforma constitucional en materia de derechos humanos en el Diario Oficial de la Federación el 10 de junio de 2011, toda vez que se reconoce que todas las personas tienen los derechos humanos previstos en la Constitución.

\section{Ley General para la Inclusión de las Personas con Discapacidad}

Esta ley fue publicada en el Diario Oficial de la Federación el 30 de 
mayo de 2011, abrogando así la Ley General de las Personas con Discapacidad publicada el 10 de junio de 2005. El objeto de esta nueva ley es reglamentar las condiciones en las que el Estado deberá promover, proteger y asegurar el pleno ejercicio de los derechos humanos de las personas con discapacidad asegurando su inclusión a la sociedad.

De manera enunciativa y no limitativa la ley reconoce a las personas con discapacidad una serie de derechos como son:

Salud y asistencia social

Trabajo y empleo

Educación

Accesibilidad y vivienda

Transporte público y comunicaciones

Desarrollo social

Deporte, recreación, cultura y turismo

Acceso a la justicia

Libertad de expresión, opinión y acceso a la información

(...) las personas con discapacidad gozarán de todos los derechos que establece el orden jurídico mexicano, sin distinción de origen étnico, nacional, género, edad, condición social, económica o de salud, religión, opiniones, estado civil, preferencias sexuales, embarazo, identidad política, lengua, situación migratoria o cualquier otra característica propia de la condición humana o que atente contra su dignidad. Las medidas contra la discriminación tienen como finalidad prevenir o corregir que una persona con discapacidad sea tratada de una manera directa o indirecta menos favorable que otra que no lo sea, en una situación comparable". (Ley General para la Inclusión de las Personas con discapacidad, 2011, art. 4)

En el desarrollo de la ley se determina la creación del Consejo Nacional para el Desarrollo y la Inclusión de las Personas con Discapacidad, el cual tiene por objeto el establecimiento de la política pública para las personas con discapacidad mediante la coordinación institucional e interinstitucional, dicho Consejo es el encargado de coordinar y elaborar el Programa Nacional para el Desarrollo y la Inclusión de las Personas con Discapacidad cuyos objetivos para el periodo 2014-2018 son los siguientes: 
a) Impulsar la realización de políticas públicas que garanticen el pleno ejercicio de los derechos de la población con discapacidad

b) Generar una cultura de la discapacidad en todos los órdenes de la vida nacional

c) Transformar el entorno público, social y privado

d) Promover el cambio cultural y de actitud en el gobierno y la sociedad respecto de las personas con discapacidad. (Programa Nacional para el Desarrollo y la Inclusión de las Personas con Discapacidad, 2014)

Para alcanzar dichos objetivos se requieren estrategias encaminadas a la protección de los derechos humanos de las personas con discapacidad; impulsar las organizaciones que promuevan la inclusión de las personas con discapacidad; elaborar acciones, proyectos y programas de desarrollo social para este sector de la población; dar seguimiento a los instrumentos internacionales de protección de las personas con discapacidad; fomentar la capacitación y el empleo en igualdad de oportunidades y con equidad; fortalecer y mejorar la calidad de los servicios de salud; garantizar el acceso al arte y a la cultura; garantizar el acceso a la justicia; garantizar la participación política, entre otras.

\section{Ley Federal para prevenir y eliminar la discriminación}

El 11 de junio de 2003, se publicó en el Diario Oficial de la Federación, que el objeto de esta ley es prevenir y eliminar todas las formas de discriminación en concordancia con el artículo $1^{\circ}$ constitucional.

En esta ley se delimita lo que debe entenderse por discriminación en la fracción III del artículo $1^{\circ}$ y lo que no es discriminación en el artículo $5^{\circ}$ de la siguiente manera

\section{Artículo $1^{\circ}$ fracción III}

Discriminación: Para los efectos de esta ley se entenderá por discriminación toda distinción, exclusión, restricción o preferencia que, por acción u omisión, con intención o sin ella, no sea objetiva, racional ni proporcional y tenga por objeto o resultado obstaculizar, restringir, impedir, menoscabar o anular el reconocimiento, goce o ejercicio de los derechos humanos y libertades, cuando se base en uno o más de los siguientes motivos: el origen étnico o nacional, el color de piel, la cultura, el sexo, el género, la edad, las discapacidades, la condición social, económica, de salud o jurídica, la religión, la apariencia 
física, las características genéticas, la situación migratoria, el embarazo, la lengua, las opiniones, las preferencias sexuales, la identidad o filiación política, el estado civil, la situación familiar, las responsabilidades familiares, el idioma, los antecedentes penales o cualquier otro motivo;

También se entenderá como discriminación la homofobia, misoginia, cualquier manifestación de xenofobia, segregación racial, antisemitismo, así como la discriminación racial y otras formas conexas de intolerancia;

Artículo $5^{\circ}$.-No se considerarán discriminatorias las acciones afirmativas que tengan por efecto promover la igualdad real de oportunidades de las personas o grupos. Tampoco será juzgada como discriminatoria la distinción basada en criterios razonables, proporcionales y objetivos cuya finalidad no sea el menoscabo de derechos. (Ley Federal para prevenir y eliminar la discriminación, p. 1)

Como se deduce de la lectura de ambos numerales estos se encuentran relacionados con los criterios de igualdad y no discriminación señalados con anterioridad, toda vez que se da la oportunidad de limitar el principio de igualdad en aras de salvaguardar los derechos y las oportunidades de algunas personas o grupos de personas, sin que con ello se viole el principio de igualdad y no discriminación.

A través de esta ley se crea el Consejo Nacional para prevenir la Discriminación, como institución rectora para promover políticas y medidas tendientes a contribuir al desarrollo cultural y social para garantizar el derecho a la igualdad. Dicho Consejo es el encargado de recibir y resolver las quejas presentadas por presuntos actos de discriminación, diseñando estrategias e instrumentos para prevenir y eliminar la discriminación.

No podemos negar que el Estado Mexicano ha buscado otorgar a las personas con discapacidad los elementos necesarios tendentes a disminuir la discriminación en contra de las personas con discapacidad para vivir con una mayor armonía en sociedad.

\section{DISCAPACIDAD EN MÉXICO Y POLÍTICAS PÚBLICAS}

En México se cuenta con una serie de programas y reglas de operación, mediante las cuales se protege a las personas con discapacidad; sin 
embargo, se requiere que las políticas públicas elaboradas sobre materia de discapacidad tengan un enfoque inclusivo, que atiendan a sus necesidades específicas en igualdad de condiciones con los demás, para lo cual se busca la concientización social y la participación activa del gobierno, las principales políticas públicas están dirigidas a lograr beneficios en educación, salud, empleo, recreación, esparcimiento, entre otros; además se hace alusión a los principios que deberán observar las políticas públicas los cuales son

(...) la equidad; la justicia social; la igualdad de oportunidades; el respeto a la evolución de las facultades de los niños y las niñas con discapacidad y de su derecho a preservar su identidad; el respeto de la dignidad inherente; la autonomía individual, incluida la libertad de tomar las propias decisiones y la independencia de las personas; la participación e inclusión plenas y efectivas en la sociedad; el respeto por la diferencia y la aceptación de la discapacidad como parte de la diversidad y la condición humanas; la accesibilidad; la no discriminación; la igualdad entre mujeres y hombres con discapacidad; y la transversalidad. (Programa Nacional para el Desarrollo y la Inclusión de las personas con Discapacidad, 2014)

Derivado del compromiso internacional que adquirió México a partir de la firma y ratificación de la Convención sobre los Derechos de las Personas con Discapacidad, se buscó que las políticas públicas en esta materia se enfocaran a los derechos, los principios y las obligaciones contenidas en la Convención, toda vez que a través de las políticas públicas se busca encarar y resolver la problemática que sufre un sector de la población, como es el caso de las personas con discapacidad.

De tal suerte que a continuación señalaremos, de manera enunciativa más no limitativa, algunos de los programas que se han implementado en México, para hacer frente a la no discriminación de las personas con discapacidad como respuesta a la protección de sus derechos.

\section{- Programa Nacional de Trabajo y Empleo para las personas con discapacidad 2014-2018}

Se encuentra enfocado a la difusión y promoción de los derechos laborales de las personas con discapacidad con pleno respeto a su dignidad, con igualdad de oportunidades y no discriminación, a través 
de las políticas que promuevan mayores oportunidades, se busca dar capacitación para el empleo y su inclusión en el sector económico; lo anterior se hace con la finalidad de eliminar las barreras que enfrentan las personas con discapacidad y que éstas se vean reconocidas en sus derechos, para alcanzar un mayor desarrollo social.

\section{- Programa de comedores comunitarios}

Con el Programa de Comedores comunitarios se pretende mejorar las condiciones nutricionales de la población, en especial a las niñas y niños, estudiantes adolescentes, mujeres embarazadas y en periodo de lactancia, personas con discapacidad, personas adultas mayores, población que sufra alguna contingencia y personas en situación de vulnerabilidad y pobreza.

Se cuenta también con un Consejo Nacional para el Desarrollo y la Inclusión de las Personas con Discapacidad (CONADIS), a través del cual se asegura el ejercicio de los derechos de tales personas, mediante la elaboración, publicación y difusión de materiales en los que se promueva la inclusión social de las personas con discapacidad.

\section{- Programas de Empleo Temporal}

Orientado a personas de 16 años o más que cuentan con ingresos disminuidos incluso personas con discapacidad, cuyo objetivo principal del programa es otorgar apoyos económicos como contraprestación por $\mathrm{su}$ participación en proyectos de beneficio social, familiar $\mathrm{o}$ comunitario, garantizando la inclusión de personas con discapacidad en igualdad de condiciones con la población, prohibiendo todo tipo de discriminación.

Con el empleo temporal, se permite a las personas con discapacidad participar en proyectos locales o regionales en instituciones públicas o privadas para que cuenten con ingresos para cubrir sus necesidades básicas y con ello continuar con la búsqueda de empleo. Empodera-T es una estrategia integral para la incorporación laboral de las personas con discapacidad que el Gobierno de la Ciudad de México presenta a través del Instituto para la Integración al Desarrollo de las Personas con Discapacidad (INDEPEDI) y la Secretaria del Trabajo y Fomento al Empleo (ST y FE). 
De acuerdo con la fracción XVI BIS del artículo 132 y la fracción I del artículo 133 de la Ley Federal del Trabajo, los patrones tienen la obligación de contar con las medidas necesarias para el acceso de personas con discapacidad y también queda prohibido negarse a aceptar trabajadores con alguna discapacidad.

Entre los incentivos que se dan a las empresas privadas al contratar a personas con discapacidad, se encuentra la deducción hasta del 100\% del Impuesto Sobre la Renta (ISR) de los ingresos de estos empleados que padezcan discapacidad motriz, mental, auditiva y de lenguaje y en un ochenta o más de la capacidad normal, siempre que el patrón pague la seguridad social de sus empleados.

También se otorgan estímulos fiscales a quien contrate adultos mayores, consistente en el $25 \%$ del salario efectivamente pagado a las personas de 65 años y más, sin embargo pese a contar con este incentivo varios supermercados no contratan a estas personas y las tienen trabajando como empaquetadores por lo que solo reciben propinas y no se encuentran aseguradas.

Otro ejemplo, es el caso de las personas con discapacidad que se encuentran en silla de ruedas y que ofrecen servicios de información a los pasajeros del Aeropuerto de la Ciudad de México, las cuales son contratadas por una empresa privada y cuentan con prestaciones de ley, con este empleo se les da la oportunidad de independencia y profesionalización de los trabajadores, llamando la atención la actitud que tiene este grupo de personas para cumplir con su trabajo ya que son más responsables.

\section{- Programa de abasto social de leche}

Dicho programa está enfocado a cumplir con el derecho social a la alimentación, facilitando el acceso a un cierto grupo de personas dentro de las que se encuentran niñas, mujeres, personas adultas mayores y personas con discapacidad.

\section{- Programa de apoyo económico a personas con discapacidad permanente en el Distrito Federal}

Se busca mejorar los ingresos económicos de las personas con discapacidad a fin de que puedan sufragar los gastos relacionados con su 
discapacidad, y al mismo tiempo otorgar servicios preventivos de salud y alimentación, a través de pláticas de orientación y materiales impresos. Sin embargo, es prioridad incorporar a mujeres y niñas al programa con la finalidad de fomentar la igualdad social y de género.

Asimismo, se han implementado políticas públicas encaminadas al libre acceso, entre ellas la Red integral de transporte para personas con discapacidad, mediante la cual cuentan con acceso gratuito al transporte público, metro y metrobus; el libre acceso al Aeropuerto Internacional de la Ciudad de México ya que se cuentan con rampas, bandas peatonales, transporte interno para su mayor comodidad, y el uso de taxi preferente en el Distrito Federal, con choferes capacitados para apoyar a las personas con discapacidad.

Es decir, las políticas públicas dan prioridad a que las personas con discapacidad cuenten con las mismas condiciones necesarias para el libre ejercicio de sus derechos y que sean incluidos en la sociedad. Así, estos son solo algunos de los programas que el gobierno mexicano ha implementado para la inclusión de las personas con discapacidad, sin embargo, aún falta mucho por hacer para alcanzar una sociedad incluyente; recordemos que las medidas que toma el Estado no son suficientes para alcanzar la igualdad y la no discriminación de las personas con discapacidad, si no se concientiza y educa a la sociedad sobre el respeto a los derechos humanos de estas personas. Al sensibilizar a la población se busca que el tema sea colocado en la opinión pública para lograr los objetivos que se plantean en las políticas públicas para alcanzar un mayor desarrollo humano.

\section{LA UNAM Y LA DISCAPACIDAD. PROGRAMAS Y AYUDA UNIVERSITARIA}

En el año de 2004, se creó el Comité de Atención para las Personas con Discapacidad en la UNAM, conformado por un grupo de profesionales y estudiantes con y sin discapacidad integrantes de la comunidad universitaria de la UNAM.

De igual forma, el 3 de diciembre de 2010 a través de la Dirección General de Cómputo y de Tecnologías de la Información y Comunicación, se inauguró la primera Aula-laboratorio de innovación para personas con discapacidad, en la que se proporciona un espacio para su acceso a las Tecnologías de la Información y Comunicación. 
La Universidad Nacional Autónoma de México, preocupada por la inclusión de las personas con discapacidad dentro de la Universidad y atendiendo a la igualdad y al respeto de los derechos humanos, se emitió un Acuerdo por el que se crea la Unidad de Atención para Personas con Discapacidad el 24 de junio de 2013, la cual tiene como objeto el ofrecer a los alumnos universitarios la orientación, información y apoyo que facilite su inclusión en la vida cotidiana tanto en el ámbito educativo, laboral, deportivo, cultural y social, para ejercer sus capacidades, habilidades y aptitudes en igualdad de oportunidades.

Para conseguir un ambiente incluyente se han acondicionado las instalaciones con rampas de acceso, cubículos y sanitarios adaptados, así como software especializado para personas con discapacidad.

De esta forma, en la Facultad de Derecho mediante acuerdo del H. Consejo Técnico de fecha 25 de marzo de 2015, se creó el Centro de Atención 'Sala Themis', el cual tiene como propósito la inclusión de las personas con discapacidad dentro de la Facultad, proporcionando las herramientas elementales que les ayuden a realizar sus actividades escolares de forma accesible.

Para cumplir con su objetivo, la sala brinda servicios dirigidos a las personas con discapacidad tales como:

I. Instalaciones adecuadas. La cuales son accesibles, debido a que hay ascensor y rampas para acceder a este piso.

Una de las discapacidades que se atienden en la sala es la de talla baja, por lo que hay escritorios especiales para este fin.

II. Equipos de cómputo. Exclusivos para personas con discapacidad y una computadora con teclado en braille.

III. Programas de cómputo especializados.

- Para ayudar a débiles visuales, se cuenta con un ampliador de pantalla,

- Programa de reconocimiento de voz para que las personas invidentes puedan redactar documentos electrónicos,

- Programa de cómputo de lectura para creación de audios, mediante el cual el estudiante presenta el material bibliográfico que necesita en audio; este material se escanea, se edita en formato digital y posteriormente se usa el software para crear el audio, y el

- Programa de cómputo lector de pantalla. 
IV. Accesorios de cómputo auxiliares. La sala cuenta con auriculares, llaves para crear perfiles de usuario en los programas de cómputo y teclado braille.

V. Impresión en braille. El estudiante presenta el material bibliográfico que necesita, este material se escanea, se edita en formato digital y posteriormente se imprime en braille.

VI. Creación de audios. A través del programa de cómputo especializado para la creación de audio lo que les permite tener acceso a distintas obras.

VII. Tifloteca. Este servicio es complementario a la impresión en braille, se cuenta con algunos ordenamientos jurídicos básicos ya impresos para su consulta.

VIII. Atención personalizada. La atención que se brinda en esta sala es personalizada y depende de la discapacidad y necesidades de cada usuario.

Así, en la Facultad de Derecho de la UNAM, se ha trabajado en la inclusión e igualdad de derechos de las personas con discapacidad, proporcionándoles un ambiente seguro para el desarrollo de sus habilidades y capacidades, garantizando los derechos humanos de este sector de la población que aún es vulnerable.

Finalmente, debemos destacar que para lograr una sociedad incluyente se requiere que el Estado garantice las herramientas y medidas necesarias para que gocen de todos sus derechos en igualdad de oportunidades y puedan acceder las personas con discapacidad al ámbito educativo, laboral, deportivo, cultural y social, eliminando así las barreras existentes para este sector de la población.

\section{CONCLUSIONES}

La discapacidad es un concepto que evoluciona, en el que se observa la interrelación entre las personas con deficiencias y las barreras que evitan su participación plena en la sociedad.

La protección de los derechos de toda persona debe ser acorde con los principios de igualdad y no discriminación, sin embargo resulta valido dar un trato desigual de iure o de facto respecto de personas o grupo de personas, como es el caso de las mujeres, ya que depende de circunstancias sociales, económicas, culturales, políticas o jurídicas que se encuentren presentes en el momento de tomar la decisión de dar un trato desigual por estar expuestas a un mayor riesgo. 
Existen diversos instrumentos internacionales y nacionales que protegen los derechos humanos de las personas con discapacidad, en las que se advierte la preocupación por erradicar la discriminación hacia este sector de la población. Entre ellos, de nivel internacional tenemos la Declaración Universal de Derechos Humanos, el Pacto internacional de Derechos Civiles y Políticos, el Pacto Internacional de Derechos Económicos, Sociales y Culturales, la Convención sobre los Derechos de las Personas con Discapacidad, Convención Interamericana para la Eliminación de todas las formas de Discriminación contra las Personas con Discapacidad, las Normas Uniformes sobre la Igualdad de Oportunidades para las Personas con Discapacidad de las Naciones Unidas.

En el orden nacional contamos con la propia Constitución Política de los Estados Unidos Mexicanos como máximo ordenamiento en el país, la Ley General de las Personas con Discapacidad y la Ley Federal para Prevenir y Eliminar la Discriminación.

En México se han implementado diversas políticas públicas, las cuales tiene como enfoque la inclusión, para atender las necesidades especificas en igualdad de condiciones con los demás, y es a través de diversos programas que consagran principios como la equidad, la igualdad de oportunidades, el respeto a la dignidad, la participación e inclusión plena en la sociedad.

La UNAM, preocupada por la inclusión de las personas con discapacidad en los ámbitos educativo, laboral, deportivo, cultural y social, ha llevado a cabo diversas medidas para cumplir con tal fin, por ejemplo, la creación de un Comité de Atención para las Personas con Discapacidad, un Aula- laboratorio de Innovación para personas con discapacidad, una Unidad de Atención a Personas con Discapacidad, todo ello para eliminar las barreras existentes y que las personas con discapacidad tengan las mismas oportunidades, al respecto la Facultad de Derecho creó el Centro de Atención "Sala Themis" para brindar servicios a las personas con discapacidad.

\section{REFERENCIAS BIBLIOGRÁFICAS}

Asamblea Legislativa del Distrito Federal. Código Civil para el Distrito Federal. Recuperado de http://www.aldf.gob.mx/archivoc9dc6843e50163a0d2628615e069b140.pdf $>$. 
Suprema Corte de Justicia de la Nación. (2013). Dignidad humana, derecho a la vida y derecho a la integridad personal. Serie Derechos Humanos.

Bariffi, F,. \& Palacios, A (Coords.). (2008). Capacidad Jurídica y Discapacidad: (estudio de derecho privado comparado a la luz de la Convención Internacional sobre los derechos de las personas con discapacidad). Argentina: Fundación Tutelar de Extremadura.

Cámara de Diputados. Constitución Política de los Estados Unidos Mexicanos. Recuperado de <http://www.diputados.gob.mx/ LeyesBiblio/pdf/1_100715.pdf>.

Cámara de Diputados, Ley Federal para prevenir y eliminar la discriminación. Recuperado de <http://www.diputados.gob.mx/ LeyesBiblio/pdf/262.pdf>.

Cámara de Diputados. Ley General para la Inclusión de las personas con discapacidad. Recuperado de <http://www.diputados.gob.mx/ LeyesBiblio/pdf/LGIPD.pdf>.

Cliki Salud. (2013, 4 de noviembre). Presentan primera encuesta sobre discapacidad en México. Recuperado de <http://www.clikisalud.net/ presentan-primera-encuesta-sobre-discapacidad-en-mexico/>.

Código Civil para el Distrito y Territorios Federales en materia común y para toda la República en materia Federal de 1928. Recuperado de $<$ http://www.wipo.int/edocs/lexdocs/laws/es/mx/mx009es.pdf $>$.

Convención Interamericana para la Eliminación de todas las Formas de Discriminación. (1999). Recuperado de <https://www.scjn.gob.mx/ libro/InstrumentosConvencion/PAG0303.pdf $>$.

Convención sobre los Derechos de las Personas con Discapacidad. (2006). Recuperado de <https://www.scjn.gob.mx/libro/ InstrumentosConvencion/PAG0313.pdf $>$.

Diario Oficial de la Federación. (31 de diciembre de 1974). Decreto que reforma y adiciona los artículos $4^{\circ}, 5^{\circ}, 30$ y 123 de la Constitución Política de los Estados Unidos Mexicanos. Recuperado de $<$ http://www.diputados.gob.mx/LeyesBiblio/ref/dof/CPEUM_ref_079 _31dic74_ima.pdf $>$. 
Diario Oficial de la Federación. (2014, 30 de abril). Programa Nacional para el Desarrollo y la Inclusión de las personas con Discapacidad. Recuperado de <http://www.dof.gob.mx/nota_detalle.php? codigo $=5343100 \&$ fecha $=30 / 04 / 2014>$.

Organización de las Naciones Unidas. (2008). Declaración Universal de los Derechos Humanos. Recuperado de <http://www.un.org/es/ documents/udhr/index_print.shtml $>$.

Organización Mundial de la Salud. Temas de Salud Discapacidades. Recuperado de $<$ http://www.who.int/topics/disabilities/es/>.

Pacto Internacional de Derechos Civiles y Políticos. (1966). Recuperado de <http://www.ordenjuridico.gob.mx/TratInt/Derechos\%20Humanos/ D47.pdf $>$

Real Academia Española. (2014). Diccionario de la lengua española. (23. ${ }^{\mathrm{a}}$ ed.). Recuperado de $<$ http://dle.rae.es/?id=DrrD8s5 $>$.

Real Academia Española. (2014). Diccionario de la lengua española. (23. ${ }^{\text {ed. }}$.). Recuperado de $<$ http://dle.rae.es/?id=DrrzNuK $>$.

Tesis: 1a. V/2013 (10a.) Primera Sala, Seminario Judicial de la Federación y su Gaceta, Libro XVI, Enero de 2013, Tomo 1, Décima Época, pag. 630, número de registro 2002513,

Tesis aislada (Constitucional). Recuperado de $<$ http://200.38.163.178/ sjfsist/Paginas/DetalleGeneralV2.aspx?Epoca $=1 \mathrm{e} 3 \mathrm{e} 10000000000 \& A p$ endice $=1000000000000 \&$ Expresion $=$ discapacidad $\&$ Dominio $=$ Rubro, Texto\&TA_TJ $=2 \&$ Orden $=1 \&$ Clase $=$ DetalleTesisBL $\&$ NumTE $=64 \& E$ $\mathrm{pp}=20 \& \mathrm{Desde}=-100 \& \mathrm{Hasta}=-100 \&$ Inde $\mathrm{x}=1 \&$ Instancias Seleccionadas $=6,1,2,50,7 \& \mathrm{ID}=2002513 \& \mathrm{Hit}=39 \& \mathrm{IDs}=2005528,2005$ 489,2005118,2005119,2005120,2005121,2005122,2005123,2005124, 2005125,2005126,2005127,2005136,2005141,2004473,2002734,2002 $873,2002512,2002513,2002514 \&$ tipoTesis $=\&$ Semanario $=0 \&$ tabla $=>$.

Tesis $1^{\mathrm{a}}$ CLXXVI/2012 (10 época) Seminario Judicial de la Federación y su Gaceta, Libro XI, Agosto de 2012, Tomo 1. Pág. 482. No. de registro 2001303. Recuperado de <http://200.38.163.178/sjfsist/Paginas/ DetalleGeneralV2.aspx?Epoca $=1 \mathrm{e} 3 \mathrm{e} 10000000000 \&$ Apendice $=10000$ $00000000 \&$ Expresion $=$ garantizar $\% 25201 \mathrm{a} \% 2520$ igualdad $\% 2520 \mathrm{de} \%$ 2520oportunidades \%2520para\%2520que\%2520la\%2520mujer\%2520 
intervenga $\% 2520$ activamente $\% 2520 \mathrm{en} \% 25201 \mathrm{a} \% 2520 \mathrm{vida} \% 2520$ soc ial $\% 2 \mathrm{C} \% 2520$ econ $\% 25 \mathrm{C} 3 \% 25 \mathrm{~B} 3 \mathrm{mica} \% 2 \mathrm{C} \% 2520 \mathrm{pol} \% 25 \mathrm{C} 3 \% 25 \mathrm{AD}$ tica $\% 2520 \mathrm{y} \% 2520 \mathrm{jur} \% 25 \mathrm{C} 3 \% 25 \mathrm{ADdica} \% 2520 \mathrm{del} \% 2520 \mathrm{pa} \% 25 \mathrm{C} 3$ $\% 25 \mathrm{ADs} \% 2 \mathrm{C} \% 2520 \mathrm{sin} \% 2520$ distinci $\% 25 \mathrm{C} 3 \% 25 \mathrm{~B} 3 \mathrm{n} \% 2520$ alguna $\% 2520$ por $\% 2520$ causa $\% 2520 \mathrm{de} \% 2520$ su $\% 2520$ sexo $\% 2 \mathrm{C} \% 2520$ dada $\% 2520$ su $\% 2520$ calidad $\% 2520 \mathrm{de} \% 2520 \& D o m i n i o=$ Rubro,T exto\&TA $\ldots \mathrm{TJ}=2 \&$ Orden $=1 \&$ Clase $=$ DetalleTesisBL \&NumTE $=1 \&$ Epp $=20 \&$ Des $\overline{\mathrm{d}} \mathrm{e}=-100 \&$ Hasta $=-100 \&$ Inde $\mathrm{x}=0 \&$ Instancias Selec cionadas $=6,1,2,50,7 \& \mathrm{ID}=2001303 \& \mathrm{Hit}=1 \& \mathrm{IDs}=2001303 \& \mathrm{tipoTesis}=\&$ Sema nario $=0 \&$ tabla $=>$.

Tesis: 1a. XLIII/2014 (10a.) Primera Sala, Gaceta del Semanario Judicial de la Federación, Libro 3, febrero de 2014, Tomo I, Décima Época, pág. 644, Número de registro 2005528, Tesis Aislada (Constitucional). Recuperado de http://200.38.163.178/sjfsist/Paginas/ DetalleGeneralV2.aspx?Epoca $=1 \mathrm{e} 3 \mathrm{e} 10000000000 \&$ Apendice $=10000$ $00000000 \&$ Expresion $=$ discapacidad $\&$ Dominio $=$ Rubro,Texto\&TA_TJ $=2 \&$ Orden $=1 \&$ Clase $=$ DetalleTesisBL $\&$ NumTE $=64 \&$ Epp $=20 \&$ Desde $=-100 \& \mathrm{Hasta}=-100 \&$ Inde $\mathrm{x}=1 \&$ Instancias Sele c cionadas $=6,1,2,50,7 \& \mathrm{ID}=2005528 \& \mathrm{Hit}=21 \& \mathrm{IDs}=2005528,2005489,2005118$, 2005119,2005120,2005121,2005122,2005123,2005124,2005125,200 $5126,2005127,2005136,2005141,2004473,2002734,2002873,200251$ $2,2002513,2002514 \&$ tipoTesis $=\&$ Semanario $=0 \&$ tabla $=>$. 